\title{
ПСИХОЛОГИЯ РАЗВИТИЯ. АКМЕОЛОГИЯ
}

УДК 159.9

DOI: $10.17223 / 17267080 / 66 / 9$

\author{
М.О. Климова, Д.А. Циринг \\ Челябинский государственный университет (Челябинск, Россия) \\ Диагностика личностной беспомощности у подростков: \\ разработка и апробация \\ психодиагностического инструментария
}

\begin{abstract}
Исследование выполнено при поддержке Фонда поддержки молодых ученых Челябинского государственного университета и РФФИ (проект № 17-36-01097)

Описана процедура разработки и апробации методики диагностики личностной беспомощчности и самостоятельности у подростков. Приведень результаты анализа психометрических показателей опросника. Разработанная методика является первым самостоятельным инструментом диагностики личностной беспомощности, она позволяет не только упростить процедуру диагностики, но и получить представление об индивидуальных особенностях проявления отдельных структурных компонентов личностной беспомощности y испытуемых.
\end{abstract}

Ключевые слова: психодиагностика; психометрия; конструирование тестов; личностная беспомощность; самостоятельность; подростковый возраст.

Одной из существенных для любого научного психологического исследования является проблема диагностики изучаемых свойств и явлений. Особенно актуальным этот вопрос становится при исследовании малоизученных феноменов и психических особенностей, которые имеют системный характер и включают в себя ряд психологических характеристик. Одним из таких феноменов является личностная беспомощность.

Концепция личностной беспомощности (Д.А. Циринг, Е.В. Веденеева, Ю.В. Яковлева, И.В. Пономарева и др.) базируется на понимании данного феномена как «качества субъекта, представляющего собой единство определенных личностных характеристик, возникающих в результате взаимодействия внутренних условий с внешними (системой семейных взаимоотношений, опытом неконтролируемых травмирующих событий), определяющее низкий уровень субъектности, т.е. низкую способность человека преобразовывать действительность, управлять событиями собственной жизни, ставить и достигать цели, преодолевая различного рода трудности» [1. С. 185-186]. 
Личностная беспомощность представляет собой системное свойство, включающее особенности функционирования различных сфер психики: мотивационной, волевой, эмоциональной, когнитивной. Она находит свое отражение в различных областях деятельности человека, сказываясь на ее успешности $[1,2]$. При этом, согласно данным проведенных исследований, признаки личностной беспомощности обнаруживаются приблизительно у трети испытуемых [1]. Однако, несмотря на значимость данной проблемы, специального инструментария для диагностики личностной беспомощности до сих пор не существовало. Традиционно для ее выявления проводилась диагностика при помощи комплекса из четырех методик, что являлось очень трудоемким как для исследователя, так и для испытуемых. Кроме того, используемые методики не давали полной картины проявлений данного феномена у респондентов, поскольку не раскрывали содержания каждого из компонентов. В связи с этим крайне актуальным был вопрос разработки специализированной методики диагностики личностной беспомощности, которая позволила бы не только выявлять личностную беспомощность / самостоятельность средствами одного опросника, но и раскрывать ее внутренне содержание, анализируя проявления каждого из ее компонентов у испытуемых.

В настоящей работе представлен опыт авторов по разработке и апробации методики диагностики личностной беспомощности у подростков. С одной стороны, необходимость разработки данного опросника была продиктована все возрастающим интересом к проблеме с точки зрения научных исследований. В отечественной психологии изучаются структура и содержание феномена личностной беспомощности и самостоятельности, факторы их формирования (Д.А. Циринг, Ю.В. Яковлева), их взаимосвязь с успешностью деятельности на различных возрастных этапах (Е.В. Веденеева, Е.В. Забелина, М.В. Овчинников, Е.А. Евстафеева и др.), исследуются психологические функции и типы личностной беспомощности (И.В. Пономарева), изучается связь личностной беспомощности с особенностями регуляции поведения субъекта (М.О. Климова, И.В. Пономарева, Е.А. Евстафеева, Я.Н. Сизова). Применение методики в данном случае необходимо для того, чтобы сформировать выборки испытуемых с личностной беспомощностью / самостоятельностью для решения дальнейших исследовательских задач. С другой стороны, наличие диагностического инструментария необходимо для решения прикладных задач, в частности психологической коррекции личностной беспомощности и ее профилактики. С этой точки зрения разработка методики для респондентов подросткового возраста представляется особенно важной, поскольку формирование личностной беспомощности начинается уже в детском возрасте, и к подростковому периоду она может быть уже достаточно выраженной у субъекта. Тем не менее личность на данном этапе еще находится в процессе активного развития, является гибкой и достаточно чувствительной к коррекционным воздействиям. Разработанная авторами методика представляет собой стандартизированный опросник, который может применяться как для индивидуального, так и для группового исследования, что отвечает потребностям в области как научного исследования, так и прикладного. 
Анализ литературы по проблеме разработки психодиагностического инструментария [3-7] позволил нам выделить ряд ключевых этапов данного процесса, в соответствии с которыми была выстроена работа над методикой.

На первом этапе разработки психодиагностического опросника необходимы постановка цели и определение исходного теоретического концепта для будущей методики. Целью нашей работы была разработка методики диагностики личностной беспомощности и самостоятельности для респондентов подросткового возраста.

Теоретическим основанием разработанной методики выступает концепция личностной беспомощности Д.А. Циринг. Так как личностная беспомощность представляет собой системный феномен, интегрирующий в себе особенности функционирования когнитивной, мотивационной, эмоциональной и волевой сфер личности, в основу методики были заложены представления о структуре личностной беспомощности, включающей четыре компонента: мотивационный, когнитивный, эмоциональный и волевой $[1,8]$.

Мотивационный компонент личностной беспомощности характеризуют следующие особенности: экстернальный локус контроля, мотивация избегания неудач, низкая самооценка, низкий уровень притязаний, страх отвержения, недостаточная сформированность ценностных ориентаций, низкая способность к целеполаганию. Когнитивная составляющая характеризуется низкими показателями дивергентного мышления, ригидностью мышления, пессимистическим атрибутивным стилем. Эмоциональный компонент личностной беспомощности включает в себя такие характеристики, как замкнутость, равнодушие, неуверенность, склонность к чувству вины, ранимость, низкий самоконтроль, возбудимость, тревожность, депрессивность, фрустрированность. Волевой компонент включает следующие особенности: безынициативность, нерешительность, низкая сформированность таких качеств личности, как организованность, настойчивость, выдержка, монотоноустойчивость [8].

Следующий этап разработки психодиагностического инструмента спецификация теста и разработка заданий. На данном этапе, опираясь на исследования, проведенные Д.А. Циринг [1], Е.В. Веденеевой [2], Ю.В. Яковлевой [9], И.В. Пономаревой [10], отбирались и фиксировались содержательные проявления каждого из компонентов. Таким образом был создан перечень свойств, отражающих психологическое содержание личностной беспомощности, исходя из которого разрабатывались вопросы для методики. В результате методика представляет собой набор утверждений, на которые испытуемому предлагается ответить «да» или «нет». Утверждения опросника создавались с учетом возрастных особенностей подростков и наиболее типичных для них жизненных ситуаций: обучение в школе, общение с друзьями, взаимодействие с родителями.

Опросник включает 98 утверждений, которые распределены по четырем шкалам в соответствии со структурой личностной беспомощности шкалы «когнитивный компонент», «мотивационный компонент», «эмоциональный компонент» и «волевой компонент». Каждая из шкал, в свою 
очередь, включает ряд показателей, конкретизирующих содержание компонента. Шкала «когнитивный компонент» включает такие показатели, как пессимистический атрибутивный стиль, ригидность мышления, малая продуктивность дивергентного мышления. Шкала «мотивационный компонент» включает следующие показатели: экстернальный локус контроля, низкий уровень притязаний, мотивация избегания неудач, низкая самооценка. Шкала «эмоциональный компонент» основана на таких характеристиках, как повышенная тревожность, эмоциональная неустойчивость, склонность к депрессии, астения. Шкала «волевой компонент» включает показатели несамостоятельности, низкой настойчивости, низкого самообладания, нерешительности, робости. Таким образом, опросник нацелен как на диагностику общего уровня личностной беспомощности, так и на выявление ее содержания покомпонентно.

После разработки заданий и создания пробной версии опросника необходимо проведение пилотажного исследования для эмпирической апробации методики, анализа пригодности разработанных пунктов, их отбора, проверки внутренней согласованности теста [4].

В эмпирической апробации методики диагностики личностной беспомощности приняли участие 296 подростков в возрасте от 13 до 16 лет.

Опросник проверен на внутреннюю согласованность. Для изучения внутренней согласованности было подсчитано значение коэффициента одномерной надежности $\alpha$-Кронбаха. По результатам первичных подсчетов были выявлены и отсеяны пункты методики, снижающие ее надежность (изначальная версия опросника включала 123 утверждения, значение коэффициента $\alpha$-Кронбаха составило 0,639). Еще одной процедурой выявления неэффективных вопросов был частотный анализ ответов испытуемых. Он позволил выявить пункты, на которые болышинство испытуемых дают одинаковые ответы. Эти вопросы были также исключены из методики и дальнейшего анализа. После этого коэффициент Кронбаха был вычислен повторно на оставшихся пунктах методики, в итоге его значение составило 0,918 (окончательная версия опросника включает 98 утверждений). Этот результат позволяет говорить о высоком уровне внутренней согласованности пунктов методики. Также проведена проверка на внутреннюю согласованность каждой из шкал опросника по отдельности. По шкале «мотивационный компонент» значение коэффициента $\alpha$-Кронбаха составило 0,745 ; по шкале «когнитивный компонент» - 0,626; по шкале «эмоциональный компонент»- 0,866; по шкале «волевой компонент»- 0,804. Полученные данные позволяют судить о достаточном уровне внутренней согласованности шкал опросника.

На материале исследования был проведен факторный анализ показателей методики, чтобы проверить, действительно ли заложенные в методике шкалы могут быть выделены в отдельные факторы.

Критерий выборочной адекватности Кайзера-Мейера-Олкина (КМО) свидетельствовал о приемлемой адекватности выборки для факторного анализа $(0,883)$, критерий сферичности Бартлетта показал статистически достоверный результат $(p=0,000)$, что также говорит о пригодности данных для 
факторного анализа. В ходе анализа было выделено 4 фактора. При такой факторной структуре доля объяснимой дисперсии составила 70,213\%. Ниже представлена матрица факторных нагрузок после вращения, отражающая содержание каждого из факторов (табл. 1).

Таблица 1

Факторное распределение показателей методики диагностики личностной беспомощности для подростков

\begin{tabular}{|l|c|c|c|c|}
\hline \multirow{2}{*}{ Показатель } & \multicolumn{3}{c|}{ Фактор } \\
\cline { 2 - 5 } & 1 & 2 & 3 & 4 \\
\hline Астения &, 797 & & & \\
\hline Депрессия &, 787 & & & \\
\hline Эмоциональная неустойчивость &, 730 & & & \\
\hline Тревожность &, 724 & & & \\
\hline Низкое самообладание &, 694 & & & \\
\hline Низкий уровень дивергентного мышления & &, 790 & & \\
\hline Низкий уровень притязаний & &, 684 & & \\
\hline Ригидность мышления & &, 611 & & \\
\hline Экстернальный локус контроля & & &, 709 & \\
\hline Избегание неудач & & &, 574 & \\
\hline Нерешительность & & &, 544 & \\
\hline Робость & & &, 427 & \\
\hline Пессимистический атрибутивный стиль & & & &, 735 \\
\hline Несамостоятельность & & & &, 669 \\
\hline Низкая настойчивость & & & &, 562 \\
\hline Низкая самооценка & & &, 451 & \\
\hline Доля объяснимой дисперсии, \% & 25,319 & 17,865 & 14,942 & 12,087 \\
\hline
\end{tabular}

В первый фактор, доля объяснимой дисперсии которого составила 25,319\%, вошли переменные «астения», «депрессия», «эмоциональная неустойчивость», «тревожность», «низкое самообладание». Психологическое содержание данного фактора, которое заключается в повышенной утомляемости, сниженном настроении, склонности к депрессии, эмоциональной лабильности, подверженности перепадам настроения, повышенной тревожности, сниженной способности «держать себя в руках» и контролировать свое эмоциональное состояние, позволило назвать данный фактор «эмоциональная неустойчивость».

Во второй фактор с долей объяснимой дисперсии 17,865\% вошли показатели «низкий уровень дивергентного мышления», «низкий уровень притязаний» и «ригидность мышления». Данный фактор был назван «когнитивная ригидность», его психологическое содержание заключается в низком уровне креативности, сниженной способности находить новые пути решения проблем, неготовности ставить перед собой сложные задачи, неуверенности в собственных силах, низком уровне гибкости мышления.

Третий фактор, доля объяснимой дисперсии которого 14,942\%, объединил в себе показатели «экстернальный локус контроля», «мотивация избегания неудач», «нерешительность», «робость» и «низкая самооценка». Психологическое содержание данного фактора характеризуется преобладанием внешней мотивации, отношением к происходящим событиям как к не зависящим от 
самого субъекта, стремлением избежать наказания при осуществлении деятельности, а не достичь высоких результатов, неготовностью принимать самостоятельные решения, робостью, неверием в собственные силы. Исходя из этого данный фактор был назван «экстратенсивная мотивация».

В четвертый фактор с долей объяснимой дисперсии 12,087\% вошли показатели «пессимистический атрибутивный стиль», «несамостоятельность», «низкая настойчивость». Данный фактор был назван «низкая настойчивость на фоне пессимистических ожиданий», он характеризуется недостатком настойчивости в достижении целей, сниженной способностью принимать самостоятельные решения, ожиданием поддержки и контроля со стороны взрослых, склонностью к ожиданию неудач.

Анализируя содержание каждого из факторов, несложно проследить их сходство с компонентами личностной беспомощности, теоретические представления о которых стали базой для разработки описываемой методики. Фактор «эмоциональная неустойчивость», выявленный нами в ходе анализа, отражает показатели эмоционального компонента личностной беспомощности. Содержание фактора «когнитивная ригидность» согласуется с характеристиками когнитивного компонента личностной беспомощности. Фактор «экстратенсивная мотивация» можно интерпретировать как мотивационный компонент личностной беспомощности. Фактор «низкая настойчивость на фоне пессимистических ожиданий» схож по содержанию с волевым компонентом личностной беспомощности.

Тем не менее необходимо отметить, что имеются некоторые расхождения в полученной при помощи факторного анализа структуре с той, которая была заложена в методике изначально. При том что шкалы, описывающие компоненты личностной беспомощности, явно прослеживаются в полученных факторах, некоторые из показателей «перешли» из одной шкалы в другую. В частности, показатель «низкое самообладание» при разработке опросника был заложен в шкалу «волевой компонент», но в ходе факторного анализа был отнесен к фактору «эмоциональная неустойчивость». Однако подобное расхождение в теоретической и эмпирической моделях вполне объяснимо и лишь напоминает нам о том, что разделение психики на отдельные структуры всегда условно, поскольку все они функционируют в тесном взаимодействии и не могут быть строго отделены друг от друга. Очевидно, что самообладание связано как с возможностями волевого контроля поведения, так и с эмоциональными особенностями индивида. переменная «низкий уровень притязаний» в ходе факторного анализа была отнесена к фактору «когнитивная ригидность», в то время как на этапе разработки методики была заложена в качестве показателя мотивационного компонента. Такой «переход» также вполне объясним, так как уровень притязаний, выступая мотивирующим фактором, является, по сути, продуктом когнитивной оценки собственных возможностей, т.е. в равной степени связан как с мотивационной, так и с когнитивной сферой личности.

Итак, в ходе факторного анализа показателей методики подтверждена возможность выделения в разработанной методике нескольких отдельных 
шкал, описывающих компоненты личностной беспомощности: эмоциональный, мотивационный, когнитивный, волевой.

Следующим этапом подготовки психодиагностического теста является анализ надежности.

Нами проведена проверка методики на надежность половинного расщепления. Расщепление опросника на две части было произведено случайным образом. В качестве показателя надежности использован коэффициент корреляции частей опросника ( $r$-Пирсона). Показатель коэффициента корреляции половинного расщепления $(r=0,856, p=0,000)$ свидетельствует о высоком уровне надежности методики. Также нами было проведено половинное расщепление опросника по отдельным шкалам. Каждая из шкал имеет высокий уровень надежности половинного расщепления: по шкале «когнитивный компонент» получено значение коэффициента корреляции $r=0,406$ на уровне значимости $p=0,000$; по шкале «мотивационный компонент» $-r=0,490$, $p=0,000$; по шкале «эмоциональный компонент» $-r=0,790, p=0,000$; по шкале «волевой компонент» $-r=0,590, p=0,000$. Полученные данные позволяют говорить о высоком уровне надежности методики.

Далее была произведена проверка методики на ретестовую надежность. Показатель ретестовой надежности является важным для определения пригодности диагностической методики, однако может использоваться только в случае исследования психических свойств, стабильных во времени. Поскольку личностная беспомощность является устойчивым личностным образованием, применение критерия ретестовой надежности для проверки методики ее диагностики является возможным и необходимым. Следует отметить, что при проведении ретеста существует вероятность того, что испытуемые могут воспроизводить в повторном обследовании предыдущую картину ответов. В связи с этим необходим достаточный интервал между первичным и повторным тестированием. В нашем исследовании временной интервал составил 16 недель (4 месяца). В качестве показателя ретестовой надежности также использовался коэффициент корреляции $r$-Пирсона. В данной процедуре приняли участие 86 испытуемых, значение коэффициента корреляции составило $r=0,642$ при $p=0,000$. Полученный показатель позволяет судить о высокой ретестовой надежности.

Следующий этап подготовки методики - проверка валидности. В данном исследовании использовался показатель конкурентной валидности. Конкурентная валидность оценивается по корреляции разработанного теста с другими, валидность которых относительно измеряемого параметра установлена. Как уже отмечалось ранее, единой методики для диагностики изучаемого параметра до сих пор не было разработано, однако личностную беспомощность можно выявлять с помощью батареи методик, направленных на выявление уровня тревожности, депрессивности, самооценки и атрибутивного стиля. В связи с этим мы предположили, что полученные результаты с помощью разработанного опросника должны коррелировать с показателями опросников, традиционно используемых для выявления личностной беспомощности и самостоятельности: «Методика определения самооценки» 
С.А. Будасси; «Личностная шкала проявлений тревоги» в адаптации Т.А. Немчинова, В.Г. Норакидзе; «Шкала депрессии» в адаптации Т.И. Балашовой; «Опросник стиля атрибуции подростков ОСТАП» (адаптация Д.А. Циринг).

Для выявления корреляций между показателями по данным методикам и значениями, полученными по разработанной методике диагностики личностной беспомощности, использовался коэффициент корреляции $r$-Пирсона (выборка составила 103 испытуемых). Полученные результаты представлены в табл. 2.

Показатели конкурентной валидности методики диагностики личностной беспомощности (соотношение с показателями других методик по коэффициенту корреляции Пирсона)

\begin{tabular}{|l|c|c|}
\hline \multicolumn{1}{|c|}{ Методика } & $r$-Пирсона & Уровень значимости $(p)$ \\
\hline $\begin{array}{l}\text { «Опросник стиля атрибуции подростков } \\
\text { ОСТАП» Д.А. Циринг }\end{array}$ & $-0,571$ & 0,000 \\
\hline $\begin{array}{l}\text { «Шкала депрессии» в адаптации } \\
\text { Т.И. Балашовой }\end{array}$ & 0,689 & 0,000 \\
\hline $\begin{array}{l}\text { «личностная шкала проявлений тревоги» } \\
\text { в адаптации Т.А. Немчинова, }\end{array}$ & 0,789 & 0,000 \\
В.Г. Норакидзе & $-0,086$ & 0,208 \\
\hline $\begin{array}{l}\text { «Методика определения самооценки» } \\
\text { С.А. Будасси }\end{array}$ & \\
\hline
\end{tabular}

Как показали результаты, значения, полученные по методике диагностики личностной беспомощности, коррелируют на высоком уровне значимости с характеристиками атрибутивного стиля, депрессии и тревожности. Следует отметить, что взаимосвязь с показателем атрибутивного стиля носит обратный характер, поскольку у испытуемых с высокими значениями личностной беспомощности обнаруживаются низкие значения по переменной «атрибутивный стиль», т.е. склонность к пессимистическому стилю атрибуции. Также необходимо отметить, что взаимосвязь с показателем самооценки не обнаружена. Это объясняется тем, что связь между личностной беспомощностью и уровнем самооценки носит нелинейный характер. У испытуемых с личностной беспомощностью может обнаруживаться как заниженная, так и завышенная самооценка. В то время как у «самостоятельных» испытуемых преобладает адекватная самооценка.

На следующем этапе исследования была проведена стандартизация разработанной методики, которая позволяет перевести «сырые» оценки испытуемых в стандартные тестовые показатели, что дает возможность сравнивать данные, полученные у различных испытуемых, и интерпретировать их.

При стандартизации использовались данные, полученные при опросе 296 человек. Для проверки нормальности распределения был использован критерий Колмогорова-Смирнова. Результаты анализа позволяют говорить о нормальном распределении признака в выборке испытуемых $(Z=0,983$, $p=0,288)$. Поскольку распределение «сырых» оценок в группе испытуемых является нормальным, далее была проведена линейная стандартизация по традиционной методике [11], которая позволила перевести исходные данные в стены. Результаты представлены в табл. 3. 
Тестовые нормы для опросника диагностики личностной беспомощности у подростков (перевод «сырых» баллов в стены)

\begin{tabular}{|c|c|c|c|c|c|c|c|c|c|c|}
\hline Стены & 1 & 2 & 3 & 4 & 5 & 6 & 7 & 8 & 9 & 10 \\
\hline $\begin{array}{c}\text { Исходные } \\
\text { баллы }\end{array}$ & $<6$ & $6-14$ & $15-22$ & $23-30$ & $31-38$ & $39-46$ & $47-54$ & $55-62$ & $63-70$ & $>70$ \\
\hline
\end{tabular}

Таким образом, при интерпретации результатов методики диагностики личностной беспомощности у подростков и оценке выраженности данного свойства, следует руководствоваться следующими характеристиками:

1 стен - крайняя выраженность самостоятельности;

2-4 стена - самостоятельность;

5-6 стенов - промежуточные значения;

7-9 стенов - личностная беспомощность;

10 стенов - крайне выраженная личностная беспомощность.

Итак, в ходе апробации методики диагностики личностной беспомощности была проверена шкальная структура опросника при помощи факторного анализа, проведен анализ надежности, оценены ретестовая надежность и надежность половинного расщепления, проанализирована конкурентная валидность методики, проведена стандартизация. Полученные в ходе данных процедур результаты позволяют говорить о том, что методика соответствует предъявляемым требованиям и может быть использована в качестве инструмента диагностики личностной беспомощности и самостоятельности у подростков.

Следует отметить, что описанные этапы апробации методики являются необходимыми, но далеко не исчерпывают весь объем работы по разработке психодиагностической методики. Как отмечают Н.А. Батурин и Н.Н. Мельникова [4], важными этапами являются также описание алгоритмов обработки данных и схем анализа результатов, рецензирование, сертификация методики, подготовка руководства для пользователя и издание методики, сопровождение использования теста. В этой связи авторами планируется дальнейшая работа над методикой, в частности расширение выборки стандартизации, проведение дополнительных исследований психометрических показателей методики, публикация текста опросника и руководства по его использованию.

\section{Лumepamypa}

1. Циринг Д.А. Психология личностной беспомощности: исследование уровней субъектности. М. : Академия, 2010. 410 c.

2. Веденеева Е.В. Мотивационный компонент личностной беспомощности на разных возрастных этапах : дис. ... канд. психол. наук. Томск, 2009. 177 с.

3. Анастази А. Психологическое тестирование / пер. с англ. и общ. ред. А.А. Алексеева. 7-е междунар. изд. СПб. : Питер, 2001. 686 с.

4. Батурин Н.А., Мельникова Н.Н. Технология разработки тестов. Часть I // Вестник Южно-Уральского государственного университета. Сер. Психология. 2009. Вып. 7, № 42 (175). C. 11-25. 
5. Батурин Н.А., Мельникова Н.Н. Технология разработки тестов. Часть II // Вестник Южно-Уральского государственного университета. Сер. Психология. 2009. Вып. 6, № 30 (163). C. 4-14.

6. Бурлачук Л.Ф. Психодиагностика : учебник для вузов. СПб. : Питер, 2006. 351 с.

7. Клайн П. Справочное руководство по конструированию тестов: введение в психометрическое проектирование. Киев : Изд-во ПАН Лтд, 1994. 688 с.

8. Циринг Д.А. Личностная беспомощность у детей: структурные компоненты и их взаимосвязи // Теоретико-методологические и психологические основы коррекционноразвивающей работы психологов : материалы Междунар. науч.-практ. конф. : в 3 ч. Шадринск : Изд-во ШГПИ, 2006. Ч. 1. С. 5-11.

9. Яковлева Ю.В. Самостоятельность в студенческом возрасте (аксиологический аспект) // Вестник Томского государственного университета. 2010. № 333. С. 153-156.

10. Пономарева И.В. Личностная беспомощность подростков из семей с нарушениями взаимоотношений : дис. ... канд. психол. наук / Ин-т психологии РАН. Челябинск, 2013. $164 \mathrm{c}$.

11. Наследов А.Д. Математические методы психологического исследования. Анализ и интерпретация данных : учеб. пособие. СПб. : Речь, 2004. 392 с.

Поступила в редакциию 11.04.2017 г.; повторно 07.10.2017 г.; принята 10.10.2017 г.

\section{Сведения об авторах:}

КЛИМОВА Марина Олеговна, старший преподаватель кафедры психологии Челябинского государственного университета (Челябинск, Россия). E-mail: klimova.marina@ list.ru ЦИРИНГ Диана Александровна, ректор Челябинского государственного университета (Челябинск, Россия). E-mail 1-di@ yandex.ru

\section{PERSONAL HELPLESSNESS OF ADOLESCENTS: DESIGN AND TESTING OF PSYCHODIAGNOSTICS TECHNIQUE}

Siberian journal of psychology, 2017, 66, 130-140. DOI: 10.17223/17267080/66/9

Klimova Marina O., Tsiring Diana A., Chelyabinsk State University (Chelyabinsk, Russian Federation)

E-mail: klimova.marina@list.ru, 1-di@yandex.ru

Keywords: psychodiagnostics; psychometry; test design; personal helplessness; self-dependence; adolescence.

The article describes the process of creation and testing of an original questionnaire to diagnose personal helplessness in adolescents. Traditionally researchers use a complex of four techniques to diagnose personal helplessness, on the one hand it is time-consuming for a researcher and respondents, on the other hand, the results of such diagnostic allowed ascertaining the presence of personal helplessness or self-dependence, but they did not give any representation about the individual characteristics of structural components of personal helplessness.

The theoretical basis of the developed technique is the concept of personal helplessness (Tsiring, D.A.). The technique is based on the structure of personal helplessness, consisting of four components (motivational, cognitive, emotional and volitional). In accordance with that four scales were laid in the questionnaire. We have created the list of properties that reflect the psychological content of the personal helplessness phenomenon, and which is based on existing studies. The analysis of the internal consistency of method items demonstrated a high level of internal consistency of the whole technique $(\alpha$-Cronbach $=0,918)$, and of each scale: the cognitive component; the motivational component; the emotional component; the volitional component.

During the empirical testing, we conducted a factor analysis of method indicators, that confirmed the factor structure inherent in the questionnaire. The analysis identified 4 factors, consistent with the scales of the questionnaire, the proportion of explainable variance was 70,213 per cent. 
We tested the reliability of the technique by half-splitting and test-retest methods. The correlation coefficient of half-splitting indicates the high level of techniques reliability. The coefficient of correlation of primary and re-diagnostic results indicates the high test-retest reliability.

We also tested the method on the concurrent validity. We obtained significant correlations of the results of our questionnaire and the results of techniques which are traditionally used to diagnose personal helplessness, such as "Attribution style questionnaire for teenagers OSTAP" by D.A. Tsiring; "Scale of depression" adapted by T.I. Balashova; "Personal scale manifestations of anxiety" adapted by T.A. Nemchinov, V.G. Norakidze.

We conducted the procedure of standardization for the method.

The results of the analysis let us state that the questionnaire for personal helplessness diagnostics satisfies the requirements and can be used as a tool to diagnose personal helplessness and self-dependence of adolescents.

\section{References}

1. Tsiring, D.A. (2010) Psikhologiya lichnostnoy bespomoshchnosti: issledovanie urovney sub"ektnosti [Psychology of personal helplessness: the study of levels of subjectness]. Moscow: Akademiya.

2. Vedeneeva, E.V. (2009) Motivatsionnyy komponent lichnostnoy bespomoshchnosti na raznykh vozrastnykh etapakh [Motivational component of personal helplessness at different age stages]. Psychology Cand. Diss. Tomsk.

3. Anastazi, A. (2001) Psikhologicheskoe testirovanie [Psychological testing]. 7th ed. Translated from English by A.A. Alekseev. St. Petersburg: Piter.

4. Baturin, N.A. \& Melnikova, N.N. (2009) Tekhnologiya razrabotki testov. Chast' I [Technology of test development. Part I]. Vestnik Yuzhno-Ural'skogo gosudarstvennogo universiteta. Ser. Psikhologiya - Bulletin of South Ural State University. Psychology. 42(175). pp. 11-25.

5. Baturin, N.A. \& Melnikova, N.N. (2009) Tekhnologiya razrabotki testov. Chast' II [Technology of test development. Part II]. Vestnik Yuzhno-Ural'skogo gosudarstvennogo universiteta. Ser. Psikhologiya - Bulletin of South Ural State University. Psychology. 30(163). pp. 4-14.

6. Burlachuk, L.F. (2006) Psikhodiagnostika [Psychodiagnostics]. St. Petersburg: Piter.

7. Klayn, P. (1994) Spravochnoe rukovodstvo po konstruirovaniyu testov: vvedenie v psikhometricheskoe proektirovanie [Reference guide for test construction: An introduction to psychometric design]. Kyev: PAN Ltd.

8. Tsiring, D.A. (2006) [Personality helplessness in children: structural components and their interrelations]. Teoretiko-metodologicheskie i psikhologicheskie osnovy korrektsionnorazvivayushchey raboty psikhologov [Theoretical, Methodological and Psychological Bases of Correctional and Developing Work of Psychologists]. Proc. of the International Conference. Shadrinsk. pp. 5-11. (In Russian).

9. Yakovleva, Yu.V. (2010) Samostoyatel'nost' v studencheskom vozraste (aksiologicheskiy aspekt) [Independence in the student age (the axiological aspect)]. Vestnik Tomskogo gosudarstvennogo universiteta - Tomsk State University Journal. 333. pp. 153-156.

10. Ponomareva, I.V. (2013) Lichnostnaya bespomoshchnost' podrostkov iz semey s narusheniyami vzaimootnosheniy [Personal helplessness of adolescents from families with disabilities]. Psychology Cand. Diss. Chelyabinsk.

11. Nasledov, A.D. (2004) Matematicheskie metody psikhologicheskogo issledovaniya. Analiz $i$ interpretatsiya dannykh [Mathematical methods of psychological research. Data analysis and interpretation]. St. Petersburg: Rech'. 